CLINICAL STUDY

\title{
Lower sex hormone-binding globulin is more strongly associated with metabolic syndrome than lower total testosterone in older men: the Health in Men Study
}

\author{
S A Paul Chubb, Zoë Hyde ${ }^{1}$, Osvaldo P Almeida ${ }^{1,2}$, Leon Flicker ${ }^{1,3}$, Paul E Norman ${ }^{4}$, Konrad Jamrozik ${ }^{5}$, \\ Graeme J Hankey ${ }^{3}$ and Bu B Yeap ${ }^{3,6}$ \\ PathWest, Department of Biochemistry, Fremantle Hospital, Western Australia, 6160 Australia, ${ }^{1}$ WA Centre for Health and Ageing, ${ }^{2}$ School of Psychiatry \\ and Clinical Neurosciences, ${ }^{3}$ School of Medicine and Pharmacology and ${ }^{4}$ School of Surgery and Pathology, University of Western Australia, Western \\ Australia, 6009 Australia, ${ }^{5}$ School of Population Health and Clinical Practice, University of Adelaide, Adelaide, 5005 Australia and ${ }^{6}$ Department of \\ Endocrinology, Fremantle Hospital, Western Australia, 6160 Australia
}

(Correspondence should be addressed to B B Yeap who is now at School of Medicine and Pharmacology, Level 2, T Block, Fremantle Hospital, Western Australia 6160, Australia; Email: byeap@cyllene.uwa.edu.au)

\begin{abstract}
Background: Reduced circulating testosterone and sex hormone-binding globulin (SHBG) are implicated as risk factors for metabolic syndrome. As SHBG increases with age while testosterone declines, we examined the relative contributions of SHBG and testosterone to the risk of metabolic syndrome in older men.

Methods: We conducted a cross-sectional study of 2502 community-dwelling men aged $\geq 70$ years without known diabetes. Metabolic syndrome was defined using the National Cholesterol Education Program-Third Adult Treatment Panel (NCEP-ATPIII) criteria. Early morning fasting sera were assayed for total testosterone, SHBG and LH. Free testosterone was calculated using mass action equations.

Results: There were 602 men with metabolic syndrome (24.1\%). The risk of metabolic syndrome increased for total testosterone $<20 \mathrm{nmol} / \mathrm{l}$, SHBG $<50 \mathrm{nmol} / \mathrm{l}$ and free testosterone $<300 \mathrm{pmol} / \mathrm{l}$. In univariate analyses SHBG was associated with all five components of metabolic syndrome, total testosterone was associated with all except hypertension, and free testosterone was associated only with waist circumference and triglycerides. In multivariate analysis, both total testosterone and especially SHBG remained associated with metabolic syndrome, with odds ratios of 1.34 (95\% confidence interval (CI): 1.18-1.52) and 1.77 (95\% CI: 1.53-2.06) respectively. Men with hypogonadotrophic hypogonadism (total testosterone $<8 \mathrm{nmol} / \mathrm{l}, \mathrm{LH} \leq 12 \mathrm{IU} / \mathrm{l})$ had the highest prevalence of metabolic syndrome $(53 \%$, $P<0.001)$.

Conclusions: Lower SHBG is more strongly associated with metabolic syndrome than lower total testosterone in community-dwelling older men. SHBG may be the primary driver of these relationships, possibly reflecting its relationship with insulin sensitivity. Further studies should examine whether measures that raise SHBG protect against the development of metabolic syndrome in older men.
\end{abstract}

European Journal of Endocrinology 158 785-792

\section{Introduction}

Cardiovascular disease (CVD) and reduced circulating testosterone are common afflictions of older men. Significant risk factors for atherosclerosis, the most common underlying process in CVD, include obesity, insulin resistance and dyslipidaemia, often described as the metabolic syndrome. Whether the age-related decline in circulating testosterone contributes to these risk factors is an important question because the answer may provide a rationale for testosterone therapy in many men. Nevertheless, the evidence for such intervention is contradictory (1-4).
A number of studies have shown that serum testosterone levels are related to insulin resistance (5-7), other features of the metabolic syndrome $(8-11)$ and CVD $(12,13)$. However, most ( 98\%) circulating testosterone is reversibly bound to albumin and sex hormone-binding globulin (SHBG). Thus, the unbound fraction of testosterone is dependent on the concentrations of these proteins as well as the total testosterone. It has therefore been hypothesised that unbound, or 'free' testosterone and non-SHBG-bound ('bioavailable') testosterone may be better reflections of prevailing testosterone biological activity than the total testosterone (14). It is also clear that the concentration 
of SHBG in serum is modulated by insulin concentrations or insulin resistance, such that higher insulin concentrations or insulin resistance are associated with lower SHBG concentrations $(15,16)$. This relationship may well confound the relationship between total testosterone and metabolic syndrome. Of those studies that have examined both total and free or bioavailable testosterone $(5,6,8,9,11-13)$, only four $(6,8,9,12)$ have found significant associations between free or bioavailable testosterone and aspects of the metabolic syndrome.

It is well recognised that with advancing age SHBG increases, while free testosterone declines more rapidly than total testosterone (17-19). Thus, SHBG should be considered together with changes in total or free testosterone to determine the most relevant measures of androgen status in older men. Clarifying whether free testosterone concentration provides any advantage over measurement of total testosterone, and whether a strong association exists between SHBG and metabolic syndrome independently of testosterone, could help to identify older men at risk of CVD. To illuminate the associations between androgen variables and the metabolic syndrome during male ageing, we studied these features in a large sample of community-dwelling older men.

\section{Subjects and methods}

\section{Study participants}

The Health in Men Study is a prospective follow-up of older men who participated in a trial of screening for abdominal aortic aneurysms (20). Briefly, between April 1996 and January 1999, community-dwelling men resident in Perth, Western Australia, aged 65-83 years were randomly selected from the electoral roll and invited to take part, enrolment to vote being compulsory for Australian citizens. Of the 17432 eligible men, $12203(70 \%)$ participated, completing a risk factor questionnaire covering aspects of medical history and lifestyle relevant to CVD. Between October 2001 and August 2004, surviving men were invited to participate in a follow-up study. Of $\sim 9000$ surviving men, 4263 (representing $35 \%$ of those initially screened) completed a follow-up visit that included another health questionnaire, and a single early morning blood sample. Of these, sera were available for assay of hormone status in 4165 men. From these subjects we excluded men taking testosterone replacement, non-fasting men, those being treated with androgen deprivation therapy, those with prostate cancer and those reporting diabetes or the use of glucose-lowering drugs $(n=1663)$, leaving 2502 eligible subjects with fasting blood samples. Height (in centimetres), weight (in kilograms) and blood pressure were measured using standard procedures. The Human
Research Ethics Committee of the University of Western Australia approved the study protocol.

\section{Laboratory assays}

Blood samples were collected between 0800 and $1030 \mathrm{~h}$ after the subjects had fasted overnight. Serum was processed immediately and stored at $-80{ }^{\circ} \mathrm{C}$ until assayed. Serum total testosterone, SHBG and luteinizing hormone (LH) were determined by chemiluminescent immunoassays on an Immulite 2000 analyzer (Diagnostic Products Corp-Biomediq, Doncaster, Australia). Between-day imprecision (coefficient of variation) was 11.2 and $8.9 \%$ at 7.2 and $18 \mathrm{nmol} / \mathrm{l}, 6.7$ and $6.2 \%$ at 5.2 and $81 \mathrm{nmol} / \mathrm{l}$, and 6.4 and $5.8 \%$ at 2.3 and $19 \mathrm{IU} / \mathrm{l}$ for testosterone, SHBG and LH respectively. The working range of the testosterone assay was $0.7-55 \mathrm{nmol} / \mathrm{l}$; the sensitivities of the SHBG and LH assays were $2 \mathrm{nmol} / \mathrm{l}$ and $0.1 \mathrm{IU} / \mathrm{l}$ respectively. Free testosterone, specifically the portion not bound to either SHBG or albumin, was calculated from total testosterone and SHBG using mass action equations as described by Vermeulen et al. (21). Fasting serum glucose, total and high-density lipoprotein (HDL) cholesterol and triglycerides were estimated using a Roche Hitachi 917 analyzer (Roche Diagnostic GmbH). Between-day imprecision was 2.9 and $2.2 \%$ at 4.8 and $15.2 \mathrm{mmol} / \mathrm{l}, 2.3$ and $2.1 \%$ at 3.2 and $6.7 \mathrm{mmol} / \mathrm{l}, 2.4$ and $2.5 \%$ at 0.8 and $1.7 \mathrm{mmol} / \mathrm{l}$, and 4.8 and $2.4 \%$ at 0.9 and $2.0 \mathrm{mmol} / \mathrm{l}$ for glucose, cholesterol, HDL and triglycerides respectively.

\section{Definition of metabolic syndrome}

Metabolic syndrome was defined according to the NCEPATPIII classification as three or more of: waist circumference $>102 \mathrm{~cm}$, fasting plasma glucose $\geq 5.6 \mathrm{mmol} / \mathrm{l}$, fasting serum triglycerides $\geq 1.7 \mathrm{mmol} / \mathrm{l}$, HDL cholesterol $<1.03 \mathrm{mmol} / \mathrm{l}$ and blood pressure $\geq 130 / 85 \mathrm{mmHg}$ (22). We used the most recent modification of the definition, which lowered the threshold for an abnormal glucose concentration to $\geq 5.6 \mathrm{nmol} / \mathrm{l}$ (23). Men with a previous diagnosis of hypertension or taking antihypertensive therapy were regarded as fulfilling the criterion for hypertension.

\section{Exclusion of men with known diabetes}

Some of the men in the original cohort with a diagnosis of diabetes had type 1 diabetes rather than type 2 and this information was not specifically recorded. Furthermore, fasting triglyceride and HDL concentrations were not available for the substantial fraction of men with diabetes who were not fasting at the time of blood sampling. For these reasons we excluded all men with known diabetes from the study. 


\section{Classification of hypogonadal men}

Men were classified as having primary hypogonadism if their total testosterone was $<8 \mathrm{nmol} / \mathrm{l}$ and $\mathrm{LH}$ $>12 \mathrm{IU} / \mathrm{l}$, Leydig cell impairment if total testosterone was $8-15 \mathrm{nmol} / \mathrm{l}$ and $\mathrm{LH}>12 \mathrm{IU} / \mathrm{l}$, and hypogonadotrophic hypogonadism if total testosterone was $<8 \mathrm{nmol} / \mathrm{l}$ and $\mathrm{LH} \leq 12 \mathrm{IU} / \mathrm{l}(24)$.

\section{Statistical analysis}

Data were analysed with the statistical package Stata, version 10.0 (StataCorp, College Station, Texas, USA 2007). Participants were divided into two groups according to whether they met the criteria for metabolic syndrome. We used $t$-tests to compare differences between the groups with regard to body composition, blood pressure, fasting glucose, SHBG, total and free testosterone. The Mann-Whitney $U$ test was used to assess the remaining continuous variables as these were not normally distributed, and categorical variables were compared with the Pearson $\chi^{2}$ test. Binary logistic regression analyses were undertaken to explore hormonal associations with the metabolic syndrome and its components, and to obtain a graphical representation of the predicted probabilities of metabolic syndrome for a given hormone level. Because the relationship between all hormones and the metabolic syndrome did not appear to be linear, spline functions were applied to the analyses. SHBG appeared to be most strongly associated with the metabolic syndrome and its components, and was entered into a multivariate model with total testosterone to determine whether the association remained after adjustment. Variables were adjusted for each other, age and the square of testosterone and SHBG to account for linear and non-linear relationships. All odds ratios (ORs) indicate the incremental risk associated with a one-unit decrease in $Z$ score. $P<0.05$ were considered statistically significant.

\section{Results}

\section{Characteristics of study participants with and without metabolic syndrome}

The characteristics of the 2502 subjects, stratified as to their metabolic syndrome status, are shown in Table 1. The prevalence of metabolic syndrome was $24.1 \%$. There was no significant difference in the ages of the men with and without metabolic syndrome.

Men with metabolic syndrome had significantly lower mean serum testosterone, calculated free testosterone and SHBG than those without metabolic syndrome $(P<0.001$ for each). The difference in LH between the two groups of men was not statistically significant.

\section{Probability of metabolic syndrome according to hormone status}

The relationships between the probability of having metabolic syndrome and total and calculated free testosterone, SHBG and LH are shown in Fig. 1. The risk increased markedly at total testosterone $<20 \mathrm{nmol} / \mathrm{l}$ and SHBG $<50 \mathrm{nmol} / \mathrm{l}$. For calculated free testosterone, there was increased risk below $300 \mathrm{pmol} / \mathrm{l}$, but the increase in risk was much less marked than for total testosterone. There was a small increase in risk as LH fell below 4 IU/l.

\section{Risk of individual components of the metabolic syndrome according to hormone status}

Table 2 shows the prevalence of each of the components of the metabolic syndrome in this sample of men, while Table 3 shows the increase in risk of each metabolic syndrome component for one-unit decrease in $\mathrm{Z}$ score in the hormone marker. For SHBG, the odds ratios were significantly increased for each component, and for total

Table 1 Characteristics of 2502 older men with and without metabolic syndrome.

\begin{tabular}{lllr}
\hline & MetS - ve $(n=1900)$ & MetS + ve $(n=602)$ & $P$ value \\
\hline Age (years) & $76.45(74.16-79.22)$ & $76.22(74.25-78.84)$ & 0.226 \\
BMI (kg/m $\left.{ }^{2}\right)$ & $25.36 \pm 3.03$ & $29.03 \pm 3.59$ & $<0.001$ \\
Waist $(\mathrm{cm})$ & $95.45 \pm 8.33$ & $106.34 \pm 8.35$ & $<0.001$ \\
WHR & $0.95 \pm 0.06$ & $1.01 \pm 0.07$ & $<0.001$ \\
Systolic BP $(\mathrm{mmHg})$ & $146.0 \pm 20.0$ & $150.3 \pm 19.2$ & $<0.001$ \\
Diastolic BP $(\mathrm{mmHg})$ & $74.0 \pm 10.1$ & $76.5 \pm 10.0$ & $<0.001$ \\
Glucose (mmol/l) & $5.29 \pm 0.52$ & $5.80 \pm 0.88$ & $<0.001$ \\
TG $(\mathrm{mmol} / \mathrm{l})$ & $1.0(0.7-1.3)$ & $1.7(1.2-2.2)$ & $<0.001$ \\
HDL (mmol/l) & $1.4(1.3-1.7)$ & $1.1(1.0-1.4)$ & $<0.001$ \\
LDL (mmol/l) & $3.0(2.4-3.5)$ & $3.0(2.4-3.5)$ & 0.787 \\
Total cholesterol $(\mathrm{mmol} / \mathrm{l})$ & $5.0(4.3-5.6)$ & $5.0(4.3-5.7)$ & 0.280 \\
Total testosterone $(\mathrm{nmol} / \mathrm{l})$ & $16.7 \pm 5.7$ & $14.0 \pm 4.9$ & $<0.001$ \\
Free testosterone (pmol/l) & $291.2 \pm 90.8$ & $274.6 \pm 88.2$ & $<0.001$ \\
SHBG (nmol/l) & $45.5 \pm 17.0$ & $36.8 \pm 14.0$ & $<0.001$ \\
LH (IU/l) & $4.27(2.97-6.41)$ & $4.07(2.77-6.20)$ & 0.059 \\
\hline
\end{tabular}

All values are expressed as mean \pm s.D., except for age, lipids and $\mathrm{LH}$, which are median (interquartile range). BMI, body mass index; WHR, weight height ratio; $\mathrm{BP}$, blood pressure; TG, triglycerides; HDL, high density lipoprotein; LDL, low density lipoprotein; SHBG, sex hormone-binding globulin; LH, luteinizing hormone. 

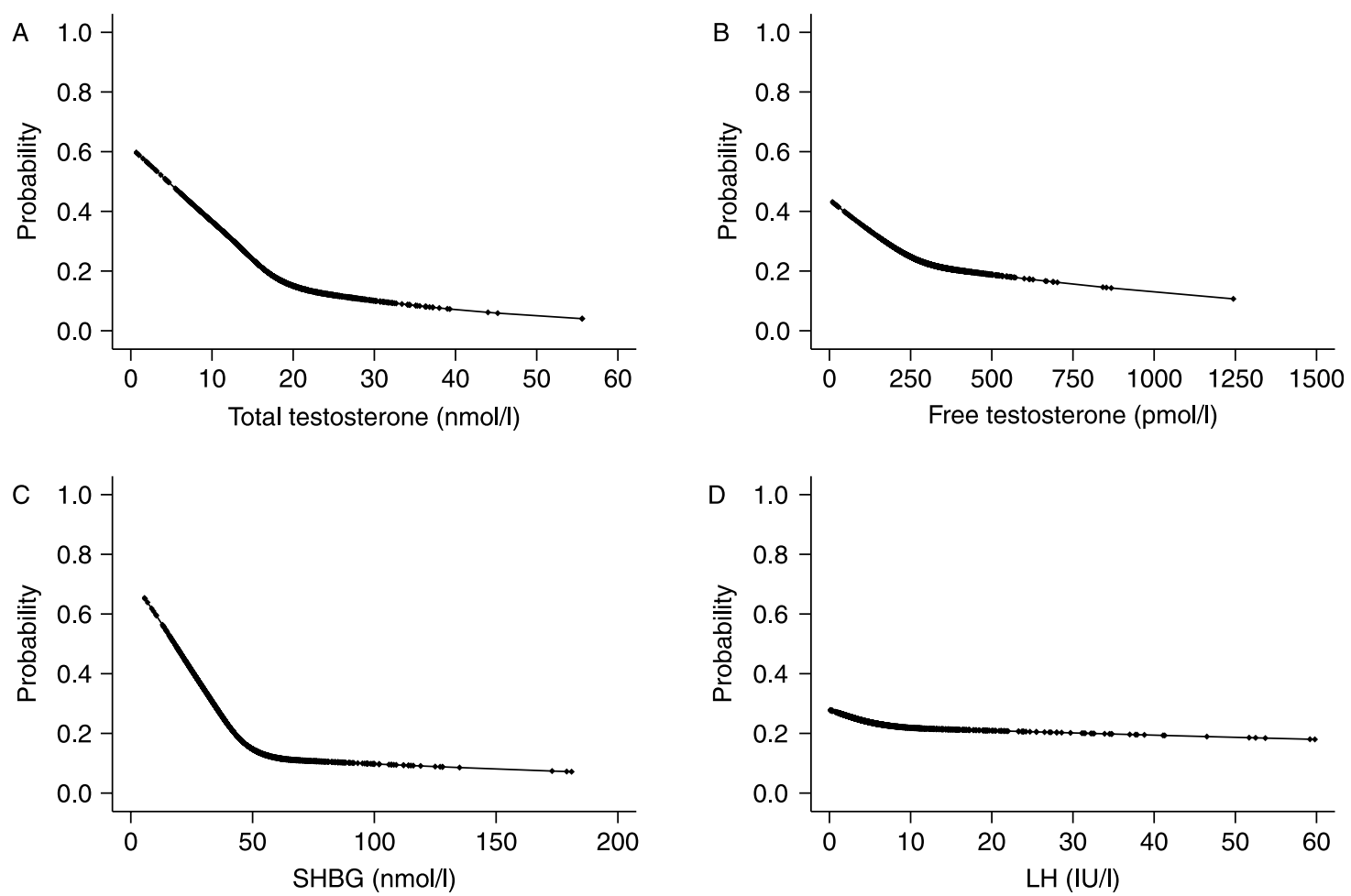

Figure 1 Relationships between probability of metabolic syndrome and total and free testosterones, sex hormone-binding globulin SHBG and luteinizing hormone LH concentrations in 2502 older men.

testosterone this was true for all components except hypertension. For free testosterone, however, the ORs were significantly increased only for waist measurement $>102 \mathrm{~cm}$ and serum triglycerides $\geq 1.7 \mathrm{mmol} / \mathrm{l}$.

\section{Multivariate analysis}

We performed multivariate logistic regression analysis to determine whether total testosterone or SHBG was more strongly associated with metabolic syndrome. Table 4 shows that in both univariate and multivariate analyses, lower SHBG was more strongly associated with metabolic syndrome than lower total testosterone, but that both these markers remained associated in the multivariate analysis.

\section{Risk of metabolic syndrome in hypogonadal men}

Table 5 shows that men characterised as having Leydig cell impairment did not have an increased risk of metabolic syndrome. Men with hypergonadotrophic hypogonadism had a higher risk of metabolic syndrome, which was not statistically significant. By contrast, those with hypogonadotrophic hypogonadism had a significantly higher risk of metabolic syndrome. The number of subjects in these groups, especially the second, is small which would reduce the power available to detect a significant association.

\section{Discussion}

We found that both SHBG and total testosterone were significantly and independently associated with metabolic syndrome in community-dwelling non-diabetic older men, but that SHBG had stronger relationships with the metabolic syndrome and each of its components when compared with total testosterone. Other studies in men spanning from middle to old age found that associations of lower total testosterone and lower SHBG with metabolic syndrome were comparable in magnitude $(8,9,11,25)$. The study by Maggio et al. (26) showed inverse correlations between metabolic

Table 2 Distribution of components of the metabolic syndrome among 2502 older men.

\begin{tabular}{lcc} 
Component & $\boldsymbol{n}$ & $\%$ \\
\hline Waist circumference $>102 \mathrm{~cm}$ & 787 & 31.5 \\
Triglycerides $\geq 1.7 \mathrm{mmol} / \mathrm{l}$ & 464 & 18.6 \\
$\mathrm{HDL}<1.03 \mathrm{mmol} / \mathrm{l}$ & 335 & 13.4 \\
Hypertension & 2195 & 88.5 \\
Glucose $\geq 5.6 \mathrm{mmol} / \mathrm{l}$ & 811 & 32.4 \\
\hline
\end{tabular}

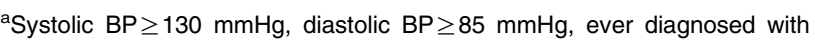
hypertension, or treatment for hypertension. 
Table 3 Univariate associations between a one-unit decrease in $Z$ score for total and free testosterone, sex hormone-binding globulin (SHBG) and presence of the components of the metabolic syndrome.

\begin{tabular}{|c|c|c|c|c|c|c|c|c|c|c|}
\hline & \multicolumn{2}{|c|}{$\begin{array}{l}\text { Waist circumfer- } \\
\text { ence }>102 \mathrm{~cm}\end{array}$} & \multicolumn{2}{|c|}{$\begin{array}{l}\text { Triglycerides } \\
\geq 1.7 \mathrm{mmol} / \mathrm{l}\end{array}$} & \multicolumn{2}{|c|}{$\begin{array}{l}\text { High density } \\
\text { lipoprotein } \\
<1.03 \mathrm{mmol} / \mathrm{l}\end{array}$} & \multicolumn{2}{|c|}{ Hypertension } & \multicolumn{2}{|c|}{ Glucose $\geq 5.6 \mathrm{mmol} / \mathrm{l}$} \\
\hline & OR & $95 \% \mathrm{Cl}$ & OR & $95 \% \mathrm{Cl}$ & OR & $95 \% \mathrm{Cl}$ & OR & $95 \% \mathrm{Cl}$ & OR & $95 \% \mathrm{Cl}$ \\
\hline SHBG & 1.66 & $1.50-1.85$ & 1.94 & $1.69-2.22$ & 1.51 & $1.31-1.75$ & 1.17 & $1.05-1.31$ & 1.21 & $1.10-1.32$ \\
\hline Total testosterone & 1.69 & $1.53-1.87$ & 1.69 & $1.50-1.91$ & 1.28 & $1.13-1.46$ & 1.10 & $0.98-1.24$ & 1.21 & $1.10-1.32$ \\
\hline Free testosterone & 1.29 & $1.17-1.41$ & 1.20 & $1.08-1.34$ & 1.00 & $0.89-1.12$ & 1.00 & $0.89-1.14$ & 1.07 & $0.99-1.17$ \\
\hline
\end{tabular}

syndrome and both total testosterone and log SHBG specifically in older men, with the latter reaching a greater level of statistical significance. Our results, showing a stronger association with metabolic syndrome for SHBG than for total testosterone are consistent with these studies. These observations suggest that the apparent association between testosterone and metabolic syndrome is secondary to the association between low SHBG and metabolic syndrome. Thus, interventions aimed at preventing metabolic syndrome in older men might be better directed at measures that increase SHBG rather than preventing or treating reduced total testosterone.

By contrast, calculated free testosterone was not independently associated with metabolic syndrome. Previous studies in which lower bioavailable testosterone $(6,8,12)$ and lower calculated free testosterone $(6,9)$ were associated with metabolic syndrome involved primarily middle-aged men. Other authors have found that free testosterone is not associated with metabolic syndrome in older non-diabetic men $(11,26)$. This is of interest, as with increasing age total testosterone declines while SHBG rises (17-19, 27-29). The age-related increase in SHBG has been cast in a negative light as, at constant total testosterone, higher SHBG would be expected to reduce circulating free testosterone by providing binding sites for testosterone. However, in addition to its relationship with metabolic syndrome, lower SHBG is also associated with increased concentrations of smaller, denser low density lipoproteins and increased mortality from CVD $(30,31)$. Additionally, SHBG correlates with adiponectin, and lower levels of adiponectin are associated with metabolic syndrome $(32,33)$. Furthermore, a higher ratio of testosterone to SHBG predicts increased risk of developing metabolic syndrome (25), and in one study lower free testosterone was associated with reduced mortality from ischaemic heart disease (34). On the other hand, in older men higher free testosterone possibly preserves cognitive function (35-37). Thus, there may be divergent associations of androgens in ageing men, free testosterone correlating with cognitive function and total testosterone and SHBG with metabolic health. The relationships between free and total testosterone with a range of health outcomes should be considered in order to determine the relevance of the 'free' hormone in this context.

In older men, total testosterone and SHBG are positively and strongly correlated with $r=0.6(19,29)$. Thus, despite both total testosterone and SHBG remaining associated with metabolic syndrome in our multivariate analysis, the primary driver for the association could be SHBG since it was the more strongly associated. This is consistent with the fact that SHBG and insulin resistance are negatively correlated and metabolic syndrome is a reflection of insulin resistance $(6,8,11)$. Alternatively, given the cross-sectional nature of our study, insulin resistance could be the primary determinant of both lower SHBG and metabolic syndrome, with the association between testosterone and metabolic syndrome being a reflection of the relationship between SHBG and testosterone. Also, total testosterone decreases in moderately obese men in keeping with reduced SHBG-binding capacity, while free testosterone only decreases in severely obese men where LH pulse amplitude is reduced (38). These observations provide support for reduced SHBG and to a lesser extent total testosterone, but not free testosterone, being markers of metabolic syndrome. Further studies would be needed to determine whether SHBG possesses any value as a surrogate marker for insulin sensitivity in tracking responses to improvements in lifestyle such as weight reduction, healthier eating and increased exercise.

Table 4 Univariate and multivariate associations between a one-unit decrease in $Z$ score for total testosterone and sex hormone-binding globulin (SHBG) and presence of the metabolic syndrome.

\begin{tabular}{|c|c|c|c|c|c|c|}
\hline & \multicolumn{3}{|c|}{ Univariate } & \multicolumn{3}{|c|}{ Multivariate $^{a}$} \\
\hline & OR & $95 \% \mathrm{Cl}$ & $P$ value & OR & $95 \% \mathrm{Cl}$ & $P$ value \\
\hline $\begin{array}{l}\text { Total testosterone } \\
\text { SHBG }\end{array}$ & $\begin{array}{l}1.78 \\
2.04\end{array}$ & $\begin{array}{l}1.59-1.99 \\
1.80-2.31\end{array}$ & $\begin{array}{l}<0.001 \\
<0.001\end{array}$ & $\begin{array}{l}1.34 \\
1.77\end{array}$ & $\begin{array}{l}1.18-1.52 \\
1.53-2.06\end{array}$ & $\begin{array}{l}<0.001 \\
<0.001\end{array}$ \\
\hline
\end{tabular}

${ }^{\mathrm{a}} \mathrm{Age}$, total testosterone, SHBG and the squares of total testosterone and SHBG were entered into the multivariate model. 
Table 5 Prevalence of metabolic syndrome in men with different categories of hypogonadism.

\begin{tabular}{|c|c|c|c|c|c|}
\hline & \multicolumn{2}{|c|}{ MetS - ve } & \multicolumn{2}{|c|}{ MetS + ve } & \multirow[b]{2}{*}{$P$ value } \\
\hline & $n$ & $\%$ & $n$ & $\%$ & \\
\hline $\begin{array}{l}\text { Leydig cell impairment } \\
\text { Total testosterone } 8-15 \mathrm{nmol} / \mathrm{l} \\
\text { LH }>12 \text { IU/l }\end{array}$ & 61 & 76 & 19 & 24 & 0.947 \\
\hline $\begin{array}{l}\text { Hypergonadotrophic hypogonadism } \\
\text { Total testosterone }<8 \mathrm{nmol} / \mathrm{I} \\
\text { LH }>12 \text { IU/I }\end{array}$ & 18 & 62 & 11 & 38 & 0.079 \\
\hline $\begin{array}{l}\text { Hypogonadotrophic hypogonadism } \\
\text { Total testosterone }<8 \mathrm{nmol} / \mathrm{l} \\
\mathrm{LH} \leq 12 \mathrm{IU} / \mathrm{l}\end{array}$ & 33 & 47 & 37 & 53 & $<0.001$ \\
\hline
\end{tabular}

Finally, our findings indicate that metabolic syndrome seems particularly associated with hypogonadotrophic hypogonadism, with a prevalence of 53\% in men with total testosterone $<8 \mathrm{nmol} / \mathrm{l}$ and LH $\leq 12 \mathrm{IU} / \mathrm{l}$. By contrast, the prevalence in men with hypergonadotrophic hypogonadism (testosterone $<8 \mathrm{nmol} / \mathrm{l}$ and LH $>12 \mathrm{IU} / \mathrm{l}$ ) was only $38 \%$. While the latter difference was of borderline statistical significance possibly due to the relatively small number of men involved, it is nevertheless consistent with the study by Bojesen et al. which found that metabolic syndrome was present in $44 \%$ of men with Klinefelter's syndrome (39). Thus, men with hypo- and hypergonadotrophic hypogonadism appear to have an increased prevalence of metabolic syndrome. However, further investigation is warranted to determine whether these conditions distinguished by differing LH concentrations might possess distinct implications for cardiovascular health. It is possible that the weaker correlation of hypergonadotrophic hypogonadism with metabolic syndrome reflects the absence of impaired hypothalamo-pituitary gonadotrophin-releasing hormone (GnRH) function, as previously described for obese men.

Strengths of this study are the size of our cohort (2502 participants), the fact that its members were community dwelling rather than selected on the basis of some other health condition, and its involvement of men older than 70 years. Fasting blood samples were collected in the morning from each of our participants to allow analysis of fasting HDL and triglycerides, and to minimise the potential effects of circadian variation on testosterone concentrations.

Limitations of this study include the cross-sectional nature of the analysis and the use of a single blood sample. Blood sampling at a single time point offers a reasonable estimate of usual testosterone levels (40), and the scope of the study did not extend to repeated blood sampling or to assay of other hormones such as oestradiol. Also, we cannot comment on the relationship between hormones and metabolic syndrome in older men with diabetes as these men were excluded from the analysis.

Data derived using one testosterone immunoassay should not be extrapolated widely without considering the potential for different testosterone assays to give varying results (41). Additionally, calculation of free testosterone using the Vermeulen method may not correlate precisely with directly measured circulating free testosterone (42). However, immunoassay of total testosterone and calculation of free testosterone are widely accepted methods used extensively in large studies where measurement of total testosterone by mass spectrometry and free testosterone by equilibrium dialysis is impractical $(8,11,19,29)$.

In conclusion, lower SHBG is more strongly associated with metabolic syndrome than lower total testosterone in community-dwelling men above 70 years age. This may reflect the relationship between insulin sensitivity and SHBG. These findings support examination of interventions that raise circulating SHBG as a possible strategy for preventing the development of the metabolic syndrome in older men.

\section{Acknowledgements}

Hormone assays were funded by a Clinical Investigator Award to BBY from the Sylvia and Charles Viertel Charitable Foundation, New South Wales, Australia. The Health in Men Study was funded by project grants from the NHMRC Australia 279408, 379600 and 403963. The authors thank Tricia Knox and the staff of the Department of Biochemistry, PathWest, Royal Perth Hospital, Western Australia, for their assistance in performing the hormone assays, Peter Feddema from DPC-Biomediq, Australia for his assistance with sourcing hormone assay kits and reagents, and Dr Kieran McCaul, Senior Research Fellow, Centre for Health and Ageing, University of Western Australia, for his advice regarding the statistical analyses. We thank the staff and management of Shenton Park Hospital for providing space in which to conduct follow-up clinics. We especially thank all the men and staff who participated in the Western Australian Abdominal Aortic Aneurysm Programme and the Health in Men Study. 


\section{References}

1 Makhsida N, Shah J, Yan G, Fisch H \& Shabsigh R. Hypogonadism and metabolic syndrome: implications for testosterone therapy. Journal of Urology $2005 \mathbf{1 7 4} 827-834$.

2 Kapoor D, Goodwin E, Channer KS \& Jones TH. Testosterone replacement therapy improves insulin resistance, glycaemic control, visceral adiposity and hypercholesterolaemia in hypogonadal men with type 2 diabetes. European Journal of Endocrinology 2006154 899-906.

3 Haddad RM, Kennedy CC, Caples SM, Tracz MJ, Bolona ER, Sideras K, Uraga MV, Erwin PJ \& Montori VM. Testosterone and cardiovascular risk in men: a systematic review and meta-analysis of randomized placebo-controlled trials. Mayo Clinic Proceedings 200782 29-39.

4 Basu R, Man CD, Campioni M, Basu A, Nair KS, Jensen MD, Khosla S, Klee G, Toffolo G, Cobelli C \& Rizza RA. Effect of 2 years of testosterone replacement on insulin secretion, insulin action, glucose effectiveness, hepatic insulin clearance, and postprandial glucose turnover in elderly men. Diabetes Care 200730 1972-1978.

5 Endre T, Mattiasson I, Berglund G \& Hulthen UL. Low testosterone and insulin resistance in hypertension-prone men. Journal of Human Hypertension 199610 755-761.

6 Tsai EC, Matsumoto AM, Fujimoto WY \& Boyko EJ. Association of bioavailable, free, and total testosterone with insulin resistance: influence of sex hormone-binding globulin and body fat. Diabetes Care 200427 861-868.

7 Pitteloud N, Mootha VK, Dwyer AA, Hardin M, Lee H, Eriksson K-F, Tripathy D, Yialamas M, Groop L, Elahi D \& Hayes FJ. Relationship between testosterone levels, insulin sensitivity, and mitochondrial function in men. Diabetes Care 200528 1636-1642.

8 Muller M, Grobbee DE, den Tonkelaar I, Lamberts SW \& van der Schouw YT. Endogenous sex hormones and metabolic syndrome in aging men. Journal of Clinical Endocrinology and Metabolism 2005 $902618-2623$.

9 Laaksonen DE, Niskanen L, Punnonen K, Nyyssonen K, Tuomainen TP, Valkonen VP, Salonen R \& Salonen JT. Testosterone and sex hormone-binding globulin predict the metabolic syndrome and diabetes in middle-aged men. Diabetes Care 2004 27 1036-1041.

10 Kaplan SA, Meehan AG \& Shah A. The age related decrease in testosterone is significantly exacerbated in obese men with the metabolic syndrome. What are the implications for the relatively high incidence of erectile dysfunction observed in these men? Journal of Urology $2006 \mathbf{1 7 6} 1524-1527$.

11 Kupelian V, Page ST, Araujo AB, Travison TG, Bremner WI \& McKinlay JB. Low sex hormone-binding globulin, total testosterone, and symptomatic androgen deficiency are associated with development of the metabolic syndrome in nonobese men. Journal of Clinical Endocrinology and Metabolism $200691843-850$.

12 Hak AE, Witteman JC, de Jong FH, Geerlings MI, Hofman A \& Pols HA. Low levels of endogenous androgens increase the risk of atherosclerosis in elderly men: the Rotterdam study. Journal of Clinical Endocrinology and Metabolism 200287 3632-3639.

13 Svartberg J, von Muhlen D, Mathiesen E, Joakimsen O, Bonaa KH \& Stensland-Bugge E. Low testosterone levels are associated with carotid atherosclerosis in men. Journal of Internal Medicine 2006 259 576-582.

14 Diver MJ. Analytical and physiological factors affecting the interpretation of serum testosterone concentration in men. Annals of Clinical Biochemistry 200643 3-12.

15 Osuna JA, Gomez-Perez R, Arata-Bellabarba G \& Villaroel V. Relationship between BMI, total testosterone, sex hormonebinding-globulin, leptin, insulin and insulin resistance in obese men. Archives of Andrology 200652 355-361.

16 Yki-Jarvinen H, Makimattila S, Utriainen T \& Rutanen EM. Portal insulin concentrations rather than insulin sensitivity regulate serum sex hormone-binding globulin and insulin-like growth factor binding protein 1 in vivo. Journal of Clinical Endocrinology and Metabolism 199580 3227-3232.

17 Harman SM, Metter EJ, Tobin JD, Pearson J \& Blackman MR. Longitudinal effects of aging on serum total and free testosterone levels in healthy men. Journal of Clinical Endocrinology and Metabolism 200186 724-731.

18 Feldman HA, Longcope C, Derby CA, Johannes CB, Araujo AB, Coviello AD, Bremner WJ \& McKinlay JB. Age trends in the level of serum testosterone and other hormones in middle-aged men: longitudinal results from the Massachusetts Male Aging Study. Journal of Clinical Endocrinology and Metabolism 200287 589-598.

19 Orwoll E, Lambert LC, Marshall LM, Phipps K, Blank J, BarrettConnor E, Cauley J, Ensrud K \& Cummings S. Testosterone and estradiol in older men. Journal of Clinical Endocrinology and Metabolism 200691 1336-1344.

20 Norman PE, Jamrozik K, Lawrence-Brown MM, Le MT, Spencer CA, Tuohy RJ, Parsons RW \& Dickinson JA. Impact of screening on mortality from abdominal aortic aneurysm: results of a large, population-based randomised controlled trial. BMJ $2004 \mathbf{3 2 9}$ $1259-1262$.

21 Vermeulen A, Verdonck L \& Kaufman JM. A critical evaluation of simple methods for the estimation of free testosterone in serum. Journal of Clinical Endocrinology and Metabolism $1999 \mathbf{8 4}$ 3666-3672.

22 Executive Summary of The Third Report of The National Cholesterol Education Program (NCEP). Expert panel on detection, evaluation, and treatment of high blood cholesterol in adults (Adult Treatment Panel III). Journal of the American Medical Association $20012852486-2497$.

23 Alberti KGMM, Zimmet P \& Shaw J. Metabolic syndrome - a new world-wide definition. A consensus statement from the International Diabetes Federation. Diabetic Medicine 200623 469-480.

24 Conway AJ, Handelsman DJ, Lording DW, Stuckey B \& Zajac JD. Use, misuse and abuse of androgens. Medical Journal of Australia 2000172 220-224.

25 Rodriguez A, Muller DC, Metter EJ, Maggio M, Harman SM, Blackman MR \& Andres R. Aging, androgens, and the metabolic syndrome in a longitudinal study of aging. Journal of Clinical Endocrinology and Metabolism 200792 3568-3572.

26 Maggio M, Laurentani F, Ceda GP, Bandinelli S, Basaria S, Ble A, Egan J, Paolisso G, Najjar S, Metter EJ, Valenti G, Guralnik JM \& Ferrucci L. Association between hormones and metabolic syndrome in older Italian men. Journal of the American Geriatrics Society $2006 \mathbf{5 4} 1832-1838$.

27 Morley JE, Kaiser FE, Perry HM, Patrick P, Morley PMK, Stauber PM, Vellas B, Baumgartner RN \& Garry PJ. Longitudinal changes in testosterone, luteinizing hormone, and folliclestimulating hormone in healthy older men. Metabolism 199646 410-413.

28 Leifke E, Goreno V, Wichers C, von zur Muhlen A, von Buren E \& Brabant G. Age-related changes of serum sex hormones, insulinlike growth factor-1 and sex-hormone binding globulin levels in men: cross-sectional data from a healthy male cohort. Clinical Endocrinology 200053 689-695.

29 Yeap BB, Almeida OP, Hyde Z, Norman PE, Chubb SA, Jamrozik K \& Flicker L. In men older than 70 years, total testosterone remains stable while free testosterone declines with age. The Health In Men Study. European Journal of Endocrinology 2007156 585-594.

30 Kalme T, Seppala M, Qiao Q, Koistinen R, Nissinen A, Harrela M, Loukovaara M, Leinonen P \& Tuomilehto J. Sex hormone-binding globulin and insulin-like growth factor-binding protein-1 as indicators of metabolic syndrome, cardiovascular risk, and mortality in elderly men. Journal of Clinical Endocrinology and Metabolism 200590 1550-1556.

31 Haffner SM, Laakso M, Miettinen H, Mykkanen L, Karhapaa P \& Rainwater DL. Low levels of sex hormone-binding globulin and 
testosterone are associated with smaller, denser low density lipoprotein in normoglycemic men. Journal of Clinical Endocrinology and Metabolism $1996 \mathbf{8 1}$ 3697-3701.

32 Gannage-Yared M-H, Khalife S, Semman M, Fares F, Jambart S \& Halaby G. Serum adiponectin and leptin levels in relation to the metabolic syndrome, androgenic profile and somatotropic axis in healthy non-diabetic elderly men. European Journal of Endocrinology 2006155 167-176.

33 Santaniemi M, Kesaniemi YA \& Ukkola O. Low plasma adiponectin concentration is an indicator of the metabolic syndrome. European Journal of Endocrinology $2006 \mathbf{1 5 5}$ 745-750.

34 Araujo AB, Kupelian V, Page ST, Handelsman DJ, Bremner WJ \& McKinlay JB. Sex steroids and all-cause and cause-specific mortality in men. Archives of Internal Medicine 2007167 1252-1260.

35 Barrett-Connor E, Goodman-Gruen D \& Patay B. Endogenous sex hormones and cognitive function in older men. Journal of Clinical Endocrinology and Metabolism 199984 3681-3685.

36 Thilers PP, MacDonald SWS \& Herlitz A. The association between endogenous free testosterone and cognitive performance: a population-based study in 35-90 year-old men and women. Psychoneuroendocrinology 200631 565-576.

37 Yeap BB, Almeida OP, Hyde Z, Chubb SAP, Hankey GJ, Jamrozik K \& Flicker L. Higher serum free testosterone is associated with better cognitive function in older men, whilst total testosterone is not. The Health In Men Study. Clinical Endocrinology 200868 404-412.
38 Giagulli VA, Kaufman JM \& Vermeulen A. Pathogenesis of the decreased androgen levels in obese men. Journal of Clinical Endocrinology and Metabolism 1994 79 997-1000.

39 Bojesen A, Kristensen K, Birkebaek NH, Fedder J, Mosekilde L, Bennett P, Laurberg P, Frystyk J, Flyvbjerg A, Christiansen JS \& Gravholt CH. The metabolic syndrome is frequent in Klinefelter's syndrome and is associated with abdominal obesity and hypogonadism. Diabetes Care 200629 1591-1598.

40 Vermeulen A \& Verdonck G. Representativeness of a single point plasma testosterone level for the long term hormonal milieu in men. Journal of Clinical Endocrinology and Metabolism 199274 939-942.

41 Rosner W, Auchus RJ, Azziz R, Sluss PM \& Raff H. Utility, limitations, and pitfalls in measuring testosterone: an Endocrine Society Position Statement. Journal of Clinical Endocrinology and Metabolism 200792 405-413.

42 Ly LP \& Handelsman DJ. Empirical estimation of free testosterone from testosterone and sex hormone-binding globulin immunoassays. European Journal of Endocrinology 2005152 471-478.

Received 8 February 2008

Accepted 25 February 2008 